\title{
O planejamento no processo de ensino/aprendizagem: concepções e desafios
}

\author{
Mariana de Normando Lira ${ }^{1}$ \\ Emily Thaís Barbosa Neves ${ }^{2}$ \\ Maria Auxiliadora Bezerra ${ }^{3}$
}

\begin{abstract}
Resumo: Este artigo tem como objetivos identificar e discutir conceitos e desafios do ato de planejar, tanto do ponto de vista teórico, quanto da prática docente efetiva. Para tanto nos baseamos, teoricamente, em Baffi (2002), Luckesi (2011), Rojo (2001) e Libâneo (2004). Os dados de análise provêm de observações de aulas e respostas a questionário de uma professora de Francês Língua Estrangeira (FLE), que atua em uma escola de idiomas localizada na cidade de Campina Grande-PB. Os resultados evidenciaram que a concepção da professora (P1) quanto ao planejamento tem semelhanças com as dos autores e os próprios autores apresentam ideias semelhantes entre si. Características como reflexão, objetivos, "meios para alcançar fins" e considerar o tempo disponível, são abordadas tanto pelos teóricos como por P1. Em relação aos desafios, verificamos que os teóricos apresentam as dificuldades para os planejamentos mais gerais, apontando na maioria das vezes problemas dos professores em relação as suas concepções. Por sua vez, P1 apresenta desafios voltados a sua preocupação com os alunos, como o desafio de se colocar no lugar social deles e de conceber ideias aparentemente criativas que levem os alunos a aprenderem o conteúdo. Assim, pudemos perceber quão importante é o planejamento, em qualquer área, mas especialmente na profissão docente.
\end{abstract}

Palavras-chave: Planejamento. Concepções. Desafios.

\section{THE PLANNING IN THE PROCESS OF TEACHING/LEARNIING: CONCEPTIONS AND CHALLENGES}

\begin{abstract}
This article aims to identify and discuss the challenges in planning from a theoretical point of view and an effective teaching practice perspective. To do that we have based ourselves theoretically in Baffi (2002), Luckesi (2011), Rojo (2011) and Libâneo (2004). The data analyses are from observations of classes and answers to a questionnaire of a teacher of French as a Foreign Language (FFL), who works in a language school located in Campina Grande - PB. The results showed that the conception of teacher (P1) related to planning has some similarities with the authors' conceptions and the authors themselves Present similar ideas. Characteristics such as reflection, goals, "means to an end" and to consider available time, are regarded for both scholars and P1. In relation to the challenges, we verified that the scholars present some difficulties to more general planning, usually highlighting teachers' issues concerning their own conceptions while P1 presents challenges related to his/her worries with students, as the challenge of putting him/herself in place of students considering their social reality and the challenge
\end{abstract}

\footnotetext{
${ }^{1}$ Graduanda do curso de Letras-português/francês, Universidade Federal de Campina Grande. E-mail: marianalira3@hotmail.com

${ }^{2}$ Graduanda do curso de Letras-português/francês, Universidade Federal de Campina Grande. E-mail: emilythaisok@hotmail.com

${ }^{3}$ Professora, Doutora em Linguística, Universidade Federal de Campina Grande. E-mail: bezerramauxiliadora@gmail.com
} 
of conceiving ideas apparently creatives which make students to learn the content. Thus we realize that planning is important in all areas, being especially necessary in the teaching profession.

Keywords: Planning. Conceptions. Challenges.

\section{INTRODUÇÃO}

O ato de planejar é uma característica comum aos humanos e se faz presente no nosso cotidiano, visto que estamos sempre precisando nos planejar, seja em situações simples, em que muitas vezes nem percebemos que estamos planejando (por exemplo, uma ida ao cinema), seja em ocasiões especiais que exigem um planejamento mais complexo (por exemplo, a realização de um doutorado).

No sistema educacional não é diferente e, dada a sua complexidade, muitos são os tipos de planejamento encontrados neste setor. Visto que a educação formal está atrelada aos governos federal, estadual e municipal, além da iniciativa privada, formas diversas de planejamento devem ser elaboradas para atender aos objetivos de cada instância. Assim, temos o Planejamento Educacional, considerado como o mais abrangente, visto que é elaborado para orientar a educação nas esferas nacional, estadual e municipal, incorporando as políticas educacionais de governo (VASCONCELLOS, 1995); o Planejamento Curricular, que corresponde às diretrizes a serem seguidas para a elaboração de currículos escolares; o Planejamento Escolar, que se circunscreve às escolas, definindo o ensino, com base em princípios políticos, filosóficos, sociais e didático-pedagógicos; e o Planejamento de Ensino, responsável pelo que e como ensinar, no âmbito de cada área do conhecimento, atendendo aos preceitos dos planejamentos citados anteriormente.

É para esse último tipo de planejamento que voltaremos nossa atenção, com o objetivo geral de refletir sobre o planejar o ensino. Para essa reflexão, estabelecemos como objetivos específicos identificar e discutir conceitos e desafios desse ato, tanto do ponto de vista teórico, quanto da prática docente efetiva. Diversas são as razões que nos levam a estudar esse tema, tendo em vista que muito se discute sobre o planejamento no processo de ensino/aprendizagem e sobre a maneira como este vem sendo tratado. Em que pesem sua importância e a contribuição teórica existente, vemos que nem sempre ao planejamento de ensino se dá o devido valor: ora é visto como um momento 
desnecessário, de perda de tempo; ora como algo que pode ser feito individualmente, não precisando de uma ação coletiva; ou, ainda, como algo permanente que, já tendo sido elaborado em um ano, não é necessário refazer. Essas crenças vão, pouco a pouco, dando diferentes conotações ao conceito de planejamento.

Neste contexto, é importante, por um lado, que os professores repensem constantemente seus métodos de ensino atentando para que, assim, os alunos se sintam motivados a aprender e a desenvolver suas capacidades cognitivas. Por outro lado, é necessário que se reconheça e se leve em consideração as particularidades das escolas brasileiras, o perfil dos alunos e possibilidade ou não de os planejamentos se constituírem motivadores e, de fato, construtivos no processo de aprendizagem, dando resultados positivos na hora da avaliação.

Para discorrermos sobre esse assunto, organizamos este artigo em quatro itens, além desta introdução. No primeiro, descrevemos a metodologia utilizada para o desenvolvimento da pesquisa. No segundo, ponderamos acerca de alguns conceitos do ato de planejar, considerando princípios teóricos advindos da área de educação e pontos de vista de uma professora de língua estrangeira, aqui identificada como P1. No terceiro item, discorremos sobre os desafios que cercam este ato, também pautadas em princípios teóricos educacionais e pontos de vista de $\mathrm{P} 1$, ao mesmo tempo que discutimos acerca dos resultados. E, por fim, no quarto item apresentamos nossas considerações finais.

\section{PROCEDIMENTOS DE ESTUDO E COLETA DE DADOS}

Para alcançarmos nossos objetivos, nos apoiamos na literatura existente sobre a temática "Planejamento". Autores como Luckesi (2011), Libâneo (2004), Baffi (2002) e Vasconcelos (1995), no âmbito da educação, além de Rojo (2001), da área de linguística aplicada, foram relevantes para o desenvolvimento deste trabalho.

Nossa pesquisa caracteriza-se como um estudo de caso, tendo em vista que analisamos apenas uma professora (P1), que atua na área de língua estrangeira há três anos. Há um ano, leciona, na cidade de Campina Grande (PB), em uma escola de idiomas - onde coletamos nossos dados - dando aulas a duas turmas. Nossa coleta de 
dados ocorreu em dois momentos. O primeiro foram observações de aulas ministradas por P1, conforme está descrito no quadro 1:

Quadro 1 - Dados relativos às aulas observadas

\begin{tabular}{|c|c|c|c|c|c|c|c|}
\hline \multirow[b]{2}{*}{$\begin{array}{l}\text { Local das } \\
\text { observações de } \\
\text { aulas }\end{array}$} & \multirow{2}{*}{ Idioma } & \multirow{2}{*}{ Nível } & \multirow[b]{2}{*}{$\begin{array}{l}\mathbf{N}^{\circ} \text { de } \\
\text { alunos }\end{array}$} & \multicolumn{4}{|c|}{ Aulas observadas } \\
\hline & & & & Data & Quantidade & Duração & Conteúdo \\
\hline $\begin{array}{l}\text { Escola de } \\
\text { idiomas } \\
\text { (rede privada) }\end{array}$ & Francês & $\begin{array}{l}\text { Básico } \\
\text { (A1) }\end{array}$ & 12 & $\begin{array}{l}\text { Outubro } \\
2014\end{array}$ & 02 & $2 \mathrm{~h} 30 \mathrm{~min}$ & $\begin{array}{l}\text { - } \\
\text { Compreens } \\
\text { ão oral } \\
\text { (música) } \\
\text {-Vocabulário } \\
\text { (nome de } \\
\text { parentesco) } \\
\text { - Futur simple }\end{array}$ \\
\hline
\end{tabular}

Quadro elaborado por Mariana Lira, Emily Thaís e Maria Auxiliadora Bezerra para este artigo (2015).

O segundo momento foi a aplicação de um questionário escrito a que P1 respondeu, na própria escola de idiomas. Esse questionário, composto por 12 questões do tipo aberta, buscou informações que nos levassem a identificar e compreender a visão de P1 acerca do que é planejamento e quais prováveis desafios ela encontra para planejar. Em nossas discussões citamos algumas respostas de P1, tais respostas estão enumeradas de acordo com a mesma sequência que se apresentam no questionário.

De posse desses dados, elaboramos nossa análise, que está apresentada abaixo, baseada na literatura específica lida. 
Muitos têm sido os olhares dos estudiosos para o planejamento em educação, especialmente pela preocupação com as diferentes conotações que vêm sendo atribuídas a tal palavra. Neste sentido, expomos num primeiro momento diferentes visões teóricas sobre concepções e características do ato de planejar e, em seguida, apresentamos a visão de P1, analisando-a à luz da teoria lida.

Afinal, pensamos ser necessário esse cotejamento entre teoria e prática, para discutirmos conceitos e princípios apresentados por P1.

\subsection{Sob o olhar dos teóricos}

Baffi (2002) apresenta significados básicos para alguns termos que se relacionam à temática de planejamento. Em seu texto verificamos que a ideia subjacente ao planejamento é a de que se trata de algo contínuo, o processo pelo qual se estabelecem os meios para atingir os fins. Essa autora, concordando com Padilha (2001), afirma que:

\footnotetext{
$\mathrm{O}$ ato de planejar é sempre processo de reflexão, de tomada de decisão sobre a ação; processo de previsão de necessidades e racionalização de emprego de meios (materiais) e recursos (humanos) disponíveis, visando à concretização de objetivos, em prazos determinados e etapas definidas, a partir dos resultados das avaliações (BAFFI, 2002, p. 2).
}

Observamos, portanto, que nesta concepção o planejamento requer reflexão, é prognóstico, uma vez que prevê o que e como vai acontecer, para que se alcance o(s) objetivo(s). Deve ter um tempo pré-estabelecido e, por fim, deve ser acompanhado de avaliações, uma vez que os resultados destas nortearão o processo.

Ao lermos Rojo (2001), percebemos uma visão semelhante à de Baffi (2002), uma vez que considera a necessidade de que se desenvolvam metas e objetivos, organizando ações para alcançá-los e reorganizá-los quando preciso. Neste sentido a autora afirma que "no caso do planejamento educacional esse ainda exige a capacidade de definir, selecionar e organizar conteúdos que deverão ser tematizados por meios de ações didáticas distríbuidas no tempo e no espaço escolar" (ROJO, 2001, p.314). Assim como Baffi (2002), ela acredita que se deve considerar o tempo que se tem para executar o planejamento e ainda acrescenta que é preciso levar em conta o espaço escolar. 
Libâneo (2004) apresenta mais uma característica do planejamento: a coletividade. Para ele "o planejamento nunca é apenas individual, é uma prática de elaboração conjunta dos planos e sua discussão pública" (LIBÂNEO, 2004, p.150). E, portanto, além de delimitar ações eficientes, o planejamento tem de cuidar das finalidades político-sociais direcionando a ação a partir de um ponto de vista crítico. $\mathrm{O}$ autor apresenta ainda a necessidade de fazer um diagnóstico e uma análise da realidade da escola, para só assim definir os objetivos e as metas através das atividades e tarefas que serão desenvolvidas durante o processo.

Semelhantemente, Luckesi (2011) apresenta o planejamento como um modo de articular fins e meios e, portanto, não se trata de um ato neutro, mas há sempre um comprometimento ideológico. No entanto, para ele, planejar em nosso país, especialmente na área de educação, tem sido tratado como uma atividade neutra, sem comprometimentos. Ele afirma que há um senso comum de que "o ato de planejar é um ato simplesmente técnico" (p. 126), porém, se trata de um ato político-social, científico e técnico ao mesmo tempo. Assim, o autor acredita que é necessário então que o planejamento ultrapasse a dimensão técnica para que se torne um momento de decisão sobre a construção de um futuro. No que diz respeito à individualidade no ato de planejar, ele acrescenta:

Decisões individuais e isoladas não são suficientes para construir resultados de uma atividade que é coletiva. As atividades individuais e isoladas não são inócuas, mas não suficientes para produzir resultados significativos no coletivo. Tornam-se necessárias ações individuais e coletivas, ao mesmo tempo (LUCKESI, 2011, p. 134).

Vemos que assim como Libâneo (2004), Luckesi (2011) vê a coletividade como uma característica importante do planejamento. Para ele o que e o como fazer devem ser decididos conjuntamente, uma vez que a escola é composta por um conjunto de profissionais.

\subsection{Sob o olhar da professora}

De acordo com P1 a escola onde ela atua não possui nenhum documento para orientar o planejamento dos professores. Uma vez por mês ocorrem reuniões gerais de planejamento com os professores/coordenadores, "em que são oferecidos alguns 
workshops para orientar os professores a como lidar com determinadas situações em sala de aula" (Resposta 6). Assim, ela faz seus próprios planejamentos de acordo com o que aprendeu em sua formação acadêmica inicial.

Essa falta de um documento de abrangência maior para nortear os professores, nesta escola, pode ser o motivo pelo qual as respostas de P1 se restrinjam ao planejamento de aula/ensino, como podemos observar na seguinte resposta em que ela aborda as características de um planejamento: "Creio que o planejamento contenha as atividades a serem desenvolvidas em cada aula." (Resposta 7). Em nenhum momento ela cita planejamentos de maior abrangência como o educacional ou o curricular.

Ela ainda afirma que realiza seu planejamento de aulas semanalmente e nele coloca o objetivo de ensino que pretende alcançar em cada aula, o tempo disponível, atividades a serem desenvolvidas, recursos e tempo a ser dispendido em cada atividade.

Como vimos, "objetivo" e "levar em conta o tempo disponível" são algumas características importantes para Rojo (2001) e Baffi (2002), e também para P1, uma vez que todas consideram que, a partir das metas e objetivos, é que organizamos as ações para atingi-los e reorganizá-los quando preciso.

Já a "coletividade", uma característica do planejamento apresentada por Libâneo (2004) e Luckesi (2011) como indispensável, não é considerada por P1, uma vez que ela faz seu planejamento individualmente, sem acompanhamento de outros professores e/ou coordenadores da escola, e até mesmo sem orientações de um documento "maior". Embora P1 tenha feito referência a reuniões mensais para planejamento, o foco dessas reuniões não é exatamente o planejamento de aulas levando em conta as atividades que serão desenvolvidas pelo conjunto dos professores. Cabe lembrar que para Luckesi (2011) essas atividades individuais e isoladas não são suficientes para produzir resultados significativos.

Em relação ao que é planejamento e sua importância, P1 afirma:

Creio que o planejamento seja como um roteiro que norteará a condução de uma aula, a partir de objetivos específicos a serem alcançados, através de um raciocínio lógico que implique em aprendizagens concretas nas ações dos alunos. E ele é importante para que a aula não seja dada através de improvisos (que nem sempre são 
muito seguros). Eles servem para dar um pouco mais de segurança ao professor com relação à condução do ensino/aprendizagem de cada aula (Resposta 9).

De acordo com essa resposta, o conceito de planejamento se restringe à instância de aula: orienta a aula por meio de objetivos pré-definidos que devem resultar na aprendizagem concreta dos alunos. P1 o considera importante uma vez que dá segurança ao professor, pois uma aula baseada em improvisos não é segura.

P1, assim como os teóricos aqui estudados, considera que a flexibilidade é uma característica importante do planejamento. Ao ser questionada sobre a possibilidade de se alterar um planejamento, ela responde:

Sim, com certeza... sempre. O professor não pode ficar preso ao seu planejamento, até porque, a sala de aula é um espaço dinâmico, que depende muito das ações e reações dos alunos. No planejamento, temse uma ideia prévia do que acontecerá, porém, ela nem sempre se confirma. Para isso, o professor deve estar aberto as adaptações e alterações (Resposta 10).

Vemos com clareza, nesta resposta, que P1 considera o desenvolvimento dos seus alunos para saber se deve continuar ou mudar seu planejamento. Ela não o realiza "a qualquer custo" só para cumprir o que havia planejado sem se importar com a aprendizagem dos alunos (a sala de aula é um espaço dinâmico, que depende muito das ações e reações dos alunos). Outra característica do planejamento que ela aborda, e que nos recorda as considerações de Baffi (2002), é que o planejamento deve prever ações futuras que podem ou não ser confirmadas (No planejamento, tem-se uma ideia prévia do que acontecerá, porém, ela nem sempre se confirma).O quadro 2, a seguir, apresenta os conceitos e características de 'planejamento', identificados nos nossos dados de análise. 
Quadro 2 - Conceitos e características de planejamento de P1

\begin{tabular}{|l|l|}
\hline Conceito & Características \\
\hline \multirow{4}{*}{ O planejamento é um roteiro que norteará } & O planejamento é importante para que a \\
a condução de uma aula. & aula não seja dada através de improvisos. \\
& - Objetivo de ensino. \\
& - Recursos. \\
& - Atividades a serem desenvolvidas. \\
& - Tempo disponível. \\
& - No planejamento, deve ser flexível, pois, \\
& nele tem-se uma ideia prévia do que \\
& acontecer, porém, ela nem sempre se \\
& confirma. \\
& O planejamento serve para dar um pouco \\
& mais de segurança ao professor. \\
\hline
\end{tabular}

Quadro elaborado por Mariana Lira, Emily Thaís e Maria Auxiliadora Bezerra para este artigo (2015).

Para saber se os objetivos foram alcançados, P1 realiza uma atividade chamada por ela de bilan, ou balanço. Essa atividade é desenvolvida pelos alunos de modo que eles percebam que aprenderam o conteúdo (ou parte dele) ensinado na aula. Ela afirma, ainda, que também faz perguntas aos alunos ao final de cada aula.

\section{QUAIS OS DESAFIOS ENCONTRADOS?}

Muitos são os conceitos e características atribuídas ao planejamento. Esses conceitos muitas vezes sinalizam que as atividades parecem simples, fáceis de serem colocadas em prática, como se o sucesso ou fracasso de sua execução dependessem apenas dos próprios professores.

Assim, apresentamos a seguir a visão dos quatro autores que embasam este trabalho, no que diz respeito aos desafios encontrados quanto ao planejamento. Em seguida, apresentamos os desafios encontrados por P1 para fazer seu planejamento e executá-lo, uma vez que, por diversos motivos, nem sempre o que vemos na teoria é o que realmente ocorre na prática. 


\subsection{Sob o olhar dos teóricos}

Baffi (2002) aponta, como um dos complicadores para o exercício da prática de planejar, a compreensão de conceitos e seu uso adequado. O que nos parece é que para essa autora, se os professores compreenderem bem conceitos como os de planejamento, plano, programa, projeto, plano estratégico e operacional, dentre outros, esses conseguirão dar um grande passo na hora de preparar e executar o planejamento.

Para Luckesi (2011), além de que o ato de planejar em nosso país tem sido conduzido como se fosse uma atividade neutra, sem comprometimentos, temos outro desafio pelo fato de que:

Por vezes, o planejamento é apresentado e desenvolvido como se tivesse um fim em si mesmo; outras vezes, é assumido como se fosse um modo de definir a aplicação de técnicas efetivas para obter os resultados, não importando a que preço (LUCKESI, 2011, p. 125).

Neste sentido, o autor acredita que não podemos pensar no planejamento como um ato de "planejar por planejar" sem que se estabeleçam objetivos para a busca de resultados. Também, não devemos passar de um extremo para outro e colocar o planejamento em prática a qualquer custo para alcançarmos resultados.

Outro desafio se dá pelo fato de que as semanas de planejamento têm sido, de maneira geral, um modo de operacionalizar o uso de recursos, ou ainda um momento de preencher formulários. Além disto, uma das colunas deste formulário diz respeito aos conteúdos, que por sua vez tem sido preenchido de acordo com os índices do livro didático e os objetivos são criados de acordo com estes conteúdos. Esse problema está ligado ao primeiro, uma vez que ao agirmos desta maneira, estamos agindo de forma neutra.

Luckesi (2011) mostra ainda algumas dificuldades na hora de executar um planejamento como, por exemplo, o fato de um conjunto de alunos não possuir os mecanismos de assimilação de um conteúdo novo, e então seja necessário que o professor retome aquele ponto que está impedindo o andamento da aprendizagem específica com a qual se está trabalhando. Daí a importância de que o planejamento seja acompanhado pela avaliação, pois ela propicia a reorientação do processo de construção 
dos resultados esperados. Por isso o autor afirma que a execução do planejamento "é dinâmica e pode sofrer alterações e adaptações na medida em que os dados da própria execução venham exigi-las" (LUCKESI, op cit, p. 167).

Rojo (2001) reconhece que planejar não é uma tarefa fácil de ser executada, tornando-se um desafio para o professor, no entanto ela afirma que "o professor não deve encarar o planejamento como uma tarefa burocrática, imposta pelas secretarias, mero preenchimento de formulários para arquivo" (ROJO, 2001, p.315). A autora ainda aponta para as dificuldades que os professores encontram no que se refere aos materiais e suportes didáticos disponibilizados pela escola, em que há pouca ou nenhuma clareza das organizações interativas necessárias para as atividades. Ao lermos Libâneo (2004), não encontramos nenhuma exposição de possíveis desafios que possam existir tanto num planejamento geral como no realizado pelo professor ou, ainda durante sua execução.

\subsection{Sob o olhar da professora}

Ao ser questionada sobre os desafios para planejar e/ou executar o planejamento, P1 afirma que encontra muitos, durante a elaboração de seus planejamentos. No entanto, ela só apresenta dois, esses estão diretamente ligados à preocupação com seus alunos, como podemos constatar no seguinte trecho:

[...] Primeiro, me deparo com o desafio de ter que me imaginar no lugar social dos alunos, para poder pensar nas possíveis reações, dúvidas, temores e certezas dos mesmos, durante a condução de cada atividade. Ou seja, antes de levar alguma atividade para a sala de aula, primeiro eu tento me imaginar no lugar dos alunos, até mesmo para pensar: - será que essa é uma atividade condizente com o nível de aprendizagem em que eles estão? Será que ela não demanda outros conhecimentos ainda não vistos? Ou será que ela demanda um raciocínio simples demais para o nível em que eles se encontram? Segundo, vem o desafio de conceber ideias que sejam aparentemente criativas, mas que também (e principalmente) levem os alunos a, de fato, aprenderem o conteúdo. Para motivar os alunos a desenvolverem alguma atividade é preciso que eles sintam interesse por realizá-la; ou seja, é preciso pensar em ideias dinâmicas, que despertem no aluno esse interesse (Resposta 12). 
Como vemos na resposta de P1, ela procura assumir o papel de aluno e perceber o que é interessante, desafiador ou motivador para ele aprender, a fim de que ela possa decidir o que preparar para as suas aulas. O quadro 3 resume esses desafios.

Quadro 3 - Desafios encontrados por P1

\begin{tabular}{|l|l|}
\hline \multirow{2}{*}{ Desafios } & Se imaginar no lugar social do aluno. \\
\cline { 2 - 3 } & $\begin{array}{l}\text { Conceber ideias que sejam aparentemente criativas } \\
\text { e que levem os alunos a aprenderem o conteúdo. }\end{array}$ \\
\hline
\end{tabular}

Quadro elaborado por Mariana Lira, Emily Thaís e Maria Auxiliadora Bezerra para este artigo (2015).

Neste sentido, P1, durante o momento de elaboração do planejamento, se questiona sobre a adequação do planejamento, se está ou não de acordo com o nível da turma, refletindo sobre $o$ quê e $o$ como ensinar. Este aspecto nos lembra a afirmação de Luckesi (2011) quando este diz que o o quê e o como fazer devem ser decididos conjuntamente, com os diversos profissionais da escola. No entanto, P1 realiza essa atividade individualmente. Observamos, ainda, que durante seu planejamento P1 faz uma reflexão, especialmente pensando nos alunos, nas prováveis dificuldades e o interesse deles pelo conteúdo, e ainda pela maneira como esse vai ser ensinado (Me deparo com o desafio de ter que me imaginar no lugar social dos alunos, para poder pensar nas possíveis reações, dúvidas, temores e certezas dos mesmos).

P1 também demonstra consciência de que não deve levar conteúdos muito difíceis que desestimulem os alunos acarretando pensamentos negativos, de que não vão conseguir aprender o conteúdo, por exemplo (será que essa é uma atividade condizente com o nível de aprendizagem em que eles estão? Será que ela não demanda outros conhecimentos ainda não vistos?). E, também, de que não deve trabalhar conteúdos muito fáceis que não despertem o interesse dos alunos, uma vez que eles achem que já sabem e não precisam aprender (Ou será que ela demanda um raciocínio simples demais para o nível em que eles se encontram?). Neste contexto, a característica que encontramos no planejamento de P1 é de diagnóstico, uma vez que ela tenta prever $o$ que e como vai acontecer, buscando sempre alcançar seus objetivos. 
O fato de que a escola em que P1 atua não possui nenhum documento que oriente o seu ensino é um fator preocupante, uma vez que a escola, mesmo sendo de idiomas, é um ambiente coletivo e o fato de cada professor trabalhar de uma maneira diferente, baseados em concepções e métodos diferentes, pode trazer consequências negativas para o ensino/aprendizagem. Além disso, constitui uma dificuldade até mesmo para os alunos, que não ficam sabendo que concepções, métodos de ensino e avaliação e ideologias a escola segue, bem como as competências linguísticas e culturais priorizadas por ela. Ainda que P1 não tenha feito referência a este fato, acreditamos que ele também dificulta seu ato de planejar, uma vez que ela não encontra nenhum suporte amplo e coletivo que sirva de base para seu planejamento individual.

P1 pode ser considerada uma exceção, uma vez que trabalha apenas com duas turmas, compostas por poucos alunos e em apenas uma escola de idiomas. Talvez por esse motivo é que ela não apontou como dificuldade na hora de planejar e executar seu planejamento, a falta de tempo, turmas lotadas, desinteresse dos alunos, etc.

\section{CONSIDERAÇÕES FINAIS}

Nossos resultados evidenciaram que a concepção de P1 quanto ao planejamento tem semelhanças com as dos autores e os próprios autores apresentam ideias semelhantes entre si. Características como reflexão, objetivos, "meios para alcançar fins" e considerar o tempo disponível, são importantes e abordadas tanto pelos teóricos como por P1.

Em relação aos desafios, verificamos que os teóricos apresentam complicações para os planejamentos mais gerais, apontando na maioria das vezes problemas dos professores em relação as suas concepções. Apenas Luckesi (2011) e Rojo (2001) apresentam dificuldades encontradas pelos professores, porém de maneira superficial. Nenhum dos autores relatou as dificuldades dos professores em planejarem e executarem aulas no contexto das escolas, especialmente as públicas, brasileiras.

Neste contexto, percebemos quão importante é o planejamento, em qualquer área, mas especialmente na profissão docente. Planejar é um ato que nos permite seguir em frente, sem nos "perdermos" ao nos depararmos com imprevistos. É termos sempre um plano que nos passa confiança no processo de ensino e aos alunos no processo de 
aprendizagem, demostrando a eles que todas as ações em sala de aula tem um objetivo a ser alcançado.

Por fim, acreditamos que com a valorização do docente por parte do governo e com professores comprometidos com a educação do país, poderemos passar a enxergar com mais frequência casos como o de P1, que planeja as aulas e consegue - pelo número reduzido - pensar nos alunos na hora de planejar, deixando essa de ser uma exceção, para se tornar uma realidade.

\section{REFERÊNCIAS}

BAFFI, Maria Adelia Teixeira. O planejamento em educação: revisando conceitos para mudar concepções e práticas. Petrópolis, 2002. Disponível em: http://www.miniweb.com.br/educadores/Artigos/PDF/fundamentos_educacao.pdf

LIBANÊO, José Carlos. Organização e gestão da escola - Teoria e prática. 5. ed. Goiânia: Alternativa, 2004.

LUCKESI, Cipriano Carlos. Avaliação da aprendizagem escolar: estudos e proposições. 22. ed. São Paulo: Cortez, 2011.

ROJO, Roxane H.R. Modelização didática e planejamento:Duas práticas esquecidas do professor. In: KLEIMAN, Angela B. A Formação do professor: Perspectivas da linguistica aplicada. Campinas: Mercado de Letras, 2001, 3 i5. 